\title{
Engagement of Tumor Necrosis Factor mRNA by an Endotoxin-Inducible Cytoplasmic Protein
}

\author{
Cyril Gueydan, Laurent Houzet, Arnaud Marchant, André Sels, \\ Georges Huez, and Véronique Kruys \\ Laboratoire de Chimie Biologique, Département de Biologie \\ Moléculaire, Université Libre de Bruxelles, Brussels, Belgium
}

\begin{abstract}
Background: Tumor necrosis factor (TNF) production by macrophages plays an important role in the host response to infection. TNF- $\alpha$ gene expression in RAW 264.7 macrophages is predominantly regulated at the translational level. A key element in this regulation is an AU-rich (AUR) sequence located in the $3^{\prime}$ untranslated region (UTR) of TNF mRNA. In unstimulated macrophages, the translation of TNF mRNA is inhibited via this AUR sequence. Upon stimulation with LPS, this repression is overcome and translation occurs. In this study, we attempted to identify cellular proteins that interact with the AUR sequence and thereby regulate TNF mRNA translation.

Materials and Methods: RNA probes corresponding to portions of TNF mRNA 3' UTR were synthesized. These labeled RNAs were incubated with cytoplasmic extracts of either unstimulated or lipopolysaccharides (LPS)stimulated RAW 264.7 macrophages. The RNA/protein complexes formed were analyzed by gel retardation. Ultraviolet (UV) cross-linking experiments were performed to determine the molecular weight of the proteins involved in the complexes.

Results: TNF mRNA AUR sequence formed two complexes (1 and 2) of distinct electrophoretic mobilities.
\end{abstract}

While the formation of complex 1 was independent of the activation state of the macrophages from which the extracts were obtained, complex 2 was detected only using cytoplasmic extracts from LPS-stimulated macrophages. Upon UV cross-linking, two proteins, of 50 and $80 \mathrm{kD}$, respectively, were capable of binding the UAR sequence. The $50-\mathrm{kD}$ protein is likely to be part of the LPS-inducible complex 2, since its binding ability was enhanced upon LPS stimulation. Interestingly, complex 2 formation was also triggered by Sendaï virus infection, another potent activator of TNF mRNA translation in RAW 264.7 macrophages. In contrast, complex 2 was not detected with cytoplasmic extracts obtained from B and $\mathrm{T}$ cell lines which are unable to produce TNF in response to LPS. Protein tyrosine phosphorylation is required for LPS-induced TNF mRNA translation. Remarkably, the protein tyrosine phosphorylation inhibitor herbimycin A abolished LPS-induced complex 2 formation. Complex 2 was already detectable after $0.5 \mathrm{hr}$ of LPS treatment and was triggered by a minimal LPS dose of $10 \mathrm{pg} / \mathrm{ml}$.

Conclusions: The tight correlation between TNF production and the formation of an LPS-inducible cytoplasmic complex suggests that this complex plays a role in the translational regulation of TNF mRNA.

\section{INTRODUCTION}

Post-transcriptional regulatory mechanisms have been shown to play a major role in gene expression in eukaryotic cells (1-4). Several messenger RNAs (mRNAs) encoding cytokines, growth factors or oncoproteins contain a conserved AU-rich (AUR) sequence in their $3^{\prime}$ untranslated regions

Address correspondence and reprint requests to: Véronique Kruys, Laboratoire de Chimie Biologique, Département de Biologie Moléculaire, U.L.B., rue des chevaux 67, 1640 Rhode Saint Genèse, Belgium.
(UTR) (5). This sequence is composed of several repeats of the pentanucleotide AUUUA. Depending on the cell system, this sequence can either decrease mRNA stability $(6,7)$ or inhibit its translation (8).

It has been recently shown that the minimal motif that mediates mRNA degradation is the UUAUUUAUU nonanucleotide $(9,10)$. Several proteins that bind AUR sequences within cytokine or protooncogene mRNAs have been identified using cell systems where AUR sequences have been shown to have a destabilizing effect 
(11-14). The exact function of these proteins has not yet been characterized.

The translation inhibition of mRNAs by the AUR sequences has been observed in reticulocyte lysates, Xenopus oocytes (15-17) and somatic cells (18). Three octanucleotides UUAUUUAU present in the 3' UTR inhibit mRNA translation to the same extent as the natural AUR sequence. The presence of a single octanucleotide in the $3^{\prime}$ UTR is, however, sufficient to decrease significantly translation efficiency (17). The mechanism by which AUR sequences exert their translation inhibitory effect has not been elucidated. We previously demonstrated that while the interferon- $\beta$ (IFN $\beta$ ) mRNA AUR sequence inhibits translation independent of its position within the $3^{\prime}$ UTR, when it is transferred upstream of the initiation codon, the inhibitory effect is lost (16).

In RAW 264.7 macrophages, tumor necrosis factor $\alpha(\mathrm{TNF} \alpha)$ gene expression is predominantly regulated at the translational level. In unstimulated macrophages, translation of TNF mRNA is repressed by the AUR sequence within the 3' UTR. Lipopolysaccharides (LPS) treatment overcomes this repression $(19,20)$. Since the AUR sequence has no effect on TNF mRNA stability in this system (21), RAW 264.7 macrophages may be useful for identifying factors involved in mRNA translational inhibition mediated by AUR sequences.

In this study, we performed electrophoretic mobility shift assays (EMSA) using labeled RNA probes corresponding to portions of the TNF $3^{\prime}$ UTR with RAW 264.7 cytoplasmic extracts. This technique allows the detection of multimeric RNA/protein(s) complexes. The results show that TNF mRNA AUR sequence can form two complexes ( 1 and 2 ) of different electrophoretic mobilities when incubated with macrophage cytoplasmic extracts. Complex 1, of lower electrophoretic mobility, forms when extracts from both unstimulated and stimulated macrophages are used. Complex 2, of higher mobility, is only detected with extracts from TNF-producing macrophages. The time course of complex 2 formation tightly correlates with that of TNF production by RAW macrophages.

\section{MATERIALS AND METHODS}

\section{Materials}

Enzymes used for construction of the different DNA plasmids and for in vitro transcription were purchased from Gibco-BRL (Gaithersburg, MD, U.S.A.). RNAse Tl was purchased from Boehringer (Indianapolis, IN, U.S.A.). RNAse A and LPS (Escherichia coli strain 0.127:B8) were obtained from Sigma Chemical Co. (St Louis, MO, U.S.A.). Herbimycin A was purchased from Gibco-BRL. The Sendai virus was obtained from SPAFAS Inc. (Sendaï virus-cat\# 900726-CantellSPAFAS Inc., CT, U.S.A.) and has been demonstrated free of detectable amount of endotoxin contamination (22).

\section{DNA Constructs}

SP643'TNF plasmid was constructed by inserting the 507-bp Bg/II fragment corresponding to the distal part of the mouse TNF 3' UTR (23) into SP64 plasmid previously cut with BamHI. SP643'TNFAU ${ }^{-}$was synthesized by using the same strategy except that the 443-bp TNF fragment derived from the Pro-UTR $\mathrm{AU}^{-}$construct described elsewhere (22) (see Fig. 1). The $\mathrm{AU}^{+}$ probe was made by inserting a polymerase chain reaction (PCR) fragment corresponding to the AUR sequence of TNF mRNA (23) (see Fig. 1) in the Sma I site of the plasmid Bluescript KS (Stratagene, La Jolla, CA, U.S.A.). The oligonucleotides used for the PCR were: 5'-GAAGGCCTC ACAGAGCCAGCCCCCC 3' (forward primer) and 5'-CCCGGATCCGGACACCCCGGCCTTC-3' (reverse primer).

\section{In Vitro Transcription}

The SP643'TNF, SP643'TNFAU ${ }^{-}$plasmids were linearized with $E c o$ RI before in vitro transcription. The RNA probes $3^{\prime} \mathrm{TNFAU}^{+}$and $3^{\prime} \mathrm{TNFAU}^{-}$ were synthesized by in vitro transcription of the different linearized constructs with the SP6 RNA polymerase (45 units/reaction) in the presence of $660 \mu \mathrm{M}$ ATP, CTP, GTP, $66 \mu \mathrm{M}$ UTP, and $\left[\alpha-{ }^{32} \mathrm{P}\right]$ UTP $(80 \mu \mathrm{Ci} ; 800 \mathrm{Ci} / \mathrm{mmole})$. The plasmid encoding the $\mathrm{AU}^{+}$probe was linearized with $B a m \mathrm{HI}$ and the $\mathrm{AU}^{+}$probe was transcribed with the T3 RNA polymerase according to the same protocol.

\section{Cell Culture}

RAW 264.7 mouse macrophages, originally from the American Type Culture Collection (ATCC) were passaged in Dulbecco's modified Eagle's medium (Gibco BRL) supplemented with 5\% fetal bovine serum (FBS myoclone super plus, Gibco BRL) and 1\% penicillin/streptomycin so- 
A

(+332)

AGAUCUCAGGCCUUCCUACCUUCAGACCUUUCCAGACUCUU CCCUGAGGUGCAAUGCACAGCCUUCCUCACAGAGCCAGCCC CCCUCUAUUUAUAUUUGCACUUAUUAUUUAUUAUUUAU UUAUUAUUUAUUUAUUUGCUUAUGAAUGUAUUUAUUUG GAAGGCCGGGGUGUCCUGGAGGACCCAGUGUGGGAAGCUG UCUUCAGACAGACAUGUUUUCUGUGAAAACGGAGCUGAGCU GUCCCCACCUGGCCUCUCUACCUUGUUGCCUCCUCUUUUGC UUAUGUUUAAAACAAAAUAUUUAUCUAACCCAAUUGUCUUAAU AACGCUGAUUUGGUGACCAGGCUGUCGCUACAUCACUGAAC CUCUGCUCCCCACGGGAGCCGUGACUGUAAUUGCCCUACAG UCAAUUGAGAGAAAUAAAGAUCGCUUGGAAAAGAAAUGUGAU UUCUGUCUUGGGAUGAAGUCUGCAUCCAUCUCUUUGCGGAG GCCUAAAGUCUCUGGGUCCAGAUCU (+845)

B
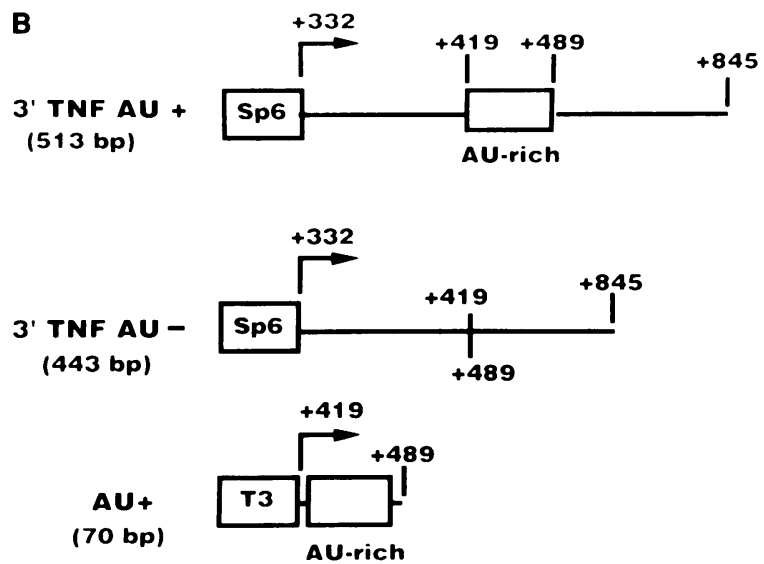

FIG. 1. Nucleotide sequence of the TNF mRNA 3' UTR from nucleotide 332 downstream of the termination codon (A) and a schematic representation of the plasmid templates used for in vitro transcription of the RNA probes (B)

(A) The sequence written in bold corresponds to the AUR sequence. The polyadenylation signal is underlined. (B) Numbers indicate nucleotide positions from the termination codon in TNF mRNA.

lution. 3B4.15 $\mathrm{T}$ cell hybridoma (originally described in Ref. 24) and A20 lymphoma B cell line (from ATCC) were cultured in RPMI 1640 medium (Gibco BRL) supplemented with 5\% FBS, $10 \mathrm{mM}$ HEPES, $2 \mathrm{mM}$ glutamine, $50 \mu \mathrm{M} \beta$-mercaptoethanol, $1 \%$ penicillin/streptomycin. LPS was added at a final concentration of $10 \mathrm{ng} / \mathrm{ml}$ in all experiments unless specified.

\section{Preparation of Macrophage Extracts}

Postribosomal extracts were prepared according to the method described by Dignam et al. (25) with some modifications. All operations were performed at $0-4^{\circ} \mathrm{C}$. Subconfluent cell cultures were rinsed once with ice-cold phosphate-buffered saline (PBS) and harvested by scraping. Cells were centrifuged at $2000 \mathrm{rpm}$, resuspended in buffer A (10 mM HEPES (pH 7.9), $1.5 \mathrm{mM}$ $\mathrm{MgCl}_{2}, 0.5 \mathrm{mM}$ DTT, $100 \mathrm{nM}$ okadaic acid, $1 \mathrm{mM}$ sodium orthovanadate, $0.5 \mathrm{mM}$ phenylmethylsulfonyl fluoride (PMSF) to a final concentration of $20 \times 10^{6}$ cells $/ 100 \mu \mathrm{l}$ and lysed by 20 strokes of Dounce homogenizer (B type pestle). Homogenates were centrifuged at $400 \times g$ for $10 \mathrm{~min}$ to pellet the nuclei and the supernatants were subsequently ultracentrifuged at $100,000 \times g$ for 90 min (Beckman rotor SW50.1). Supernatants were collected and are referred as S100 extracts in the results. Protein concentration in S100 extracts was determined by the bicinchoninic acid method (PIERCE, Rockford, IL, U.S.A.), and samples were immediately frozen at $-80^{\circ} \mathrm{C}$.

\section{Electrophoretic Mobility Shift Assay}

Electrophoretic mobility shift assays (EMSAs) were performed according to Konarska and Sharp (26), and Leibold and Munro (27). The same number of counts per minute $(50,000 \mathrm{cpm} /$ reaction) for each probe was used in the binding reaction. For the $3^{\prime} \mathrm{TNF} \mathrm{AU}^{+}$probe, $50,000 \mathrm{cpm}$ correspond to 7.6 fmoles of RNA, for the 3' TNF $\mathrm{AU}^{-}$to 11.6 fmoles and for the $\mathrm{AU}^{+}$probe to 20 fmoles. ${ }^{32} \mathrm{P}$-labeled RNA probe $(50,000 \mathrm{cpm} / \mu \mathrm{l})$ was heated at $70^{\circ} \mathrm{C}$ for $15 \mathrm{~min}$, then cooled to room temperature for $3 \mathrm{~min}$. One microliter of radiolabeled RNA was incubated for $30 \mathrm{~min}$ on ice with $20 \mu \mathrm{g}$ of $\mathrm{S} 100$ protein extract in binding buffer (20 mM HEPES, pH 7.6; $3 \mathrm{mM} \mathrm{MgCl}_{2} ; 40$ $\mathrm{mM} \mathrm{KCl} ; 2 \mathrm{mM} \mathrm{DTT} ; 5 \%$ glycerol) in a total volume of $15 \mu$ l. RNAse T1 (6 units) was added to the samples and the mixtures were further incubated for $10 \mathrm{~min}$ at room temperature. Heparin was then added at a final concentration of $5 \mathrm{mg} / \mathrm{ml}$. Three microliters of loading buffer ( $90 \%$ glycerol, $0.025 \%$ bromophenol blue) were added to the samples which were then resolved by electrophoresis on a $1 \times$ TBE nondenaturing $4 \%$ polyacrylamide gel at $4 \mathrm{~mA}$ for $14 \mathrm{hr}$ at $4^{\circ} \mathrm{C}$. Gels were dried and autoradiographed with Kodak films.

\section{UV Cross-Linking and SDS Polyacrylamide Gel Electrophoresis}

The first steps of the experiment were identical to the EMSA described above. After the addition of 
heparin, the binding mixes were irradiated with ultraviolet (UV) light for $10 \mathrm{~min}$ at $4^{\circ} \mathrm{C}$, using a Sylvania G15T8 germicidal light placed $15 \mathrm{~cm}$ above the samples. Twenty units of RNAse $\mathrm{Tl}$ and $10 \mu \mathrm{g}$ of RNAse A were added to the samples, and the mixtures were further incubated at $37^{\circ} \mathrm{C}$ for 30 min to degrade unbound RNA. An equal volume of loading buffer ( $1 \%$ SDS; $1 \%$ $\beta$-mercaptoethanol; $10 \%$ glycerol; $0.05 \mathrm{M}$ Tris, pH 6.5, $0.025 \%$ bromophenol blue) was added to the samples before heating to $100^{\circ} \mathrm{C}$ for $4 \mathrm{~min}$. The samples were analyzed by electrophoresis on a $20 \%$ polyacrylamide denaturing gel containing $0.1 \%$ SDS. ${ }^{32} \mathrm{P}$-labeled proteins were visualized by autoradiography with Kodak films.

\section{TNF Assay}

TNF production was measured in cell supernatants by sandwich enzyme-linked immunosorbent assay (ELISA) using a polyclonal rabbit antimouse TNF antibody for coating and the same polyclonal antibody that was biotinylated for detection (generously provided by Dr. Wim Buurman, University of Limburg, Maastricht, The Netherlands).

\section{RESULTS}

\section{Postribosomal Supernatant (S100) from RAW 264.7 Macrophages Contains Constitutive and Inducible Proteins Which Bind the TNF mRNA AUR Sequence}

To identify factors that interact with the AUR sequence within TNF mRNA, we performed electrophoretic mobility shift assay (EMSA) using labeled RNA probes from different regions of the TNF mRNA 3' UTR (Fig. 1). These were incubated with S100 cytoplasmic extracts obtained from RAW 264.7 cell cultured in the presence or absence of LPS (10 ng/ml for $2 \mathrm{hr}$ ). Figure 2 shows that RNA probes containing TNF mRNA AUR motifs either with $\left(3^{\prime} \mathrm{TNF} \mathrm{AU}^{+}\right)$or without $\left(\mathrm{AU}^{+}\right) 3^{\prime} \mathrm{TNF}$-flanking sequences bound a factor present in S100 cytoplasmic extracts of both unstimulated and LPS-stimulated RAW cells (complex 1). This binding activity was not detected with a TNF 3' UTR probe specifically deleted for the AUR motifs ( $3^{\prime}$ TNF $\left.\mathrm{AU}^{-}\right)$. Interestingly, the $3^{\prime} \mathrm{TNF} \mathrm{AU}^{+}$probe alone also formed a second complex (complex 2). Although this complex was hardly detectable with $\mathrm{S} 100$ extracts from unstimulated macrophages, its formation signif-

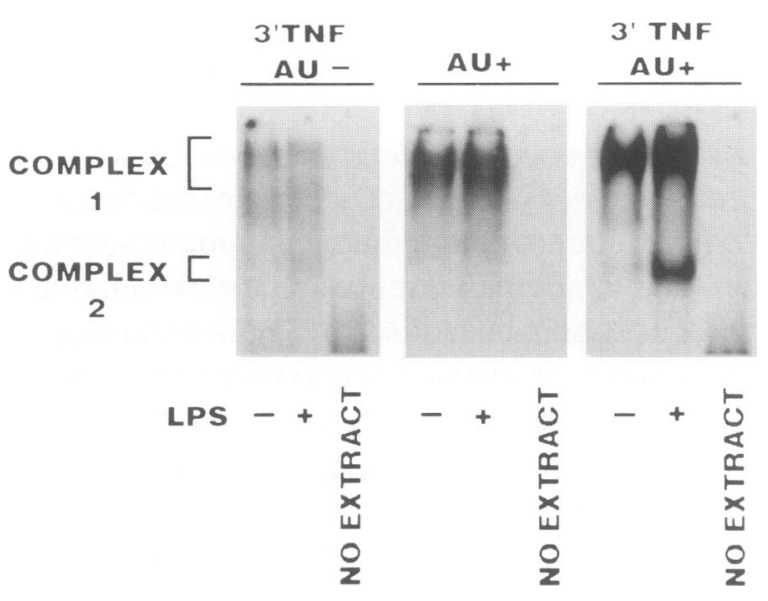

FIG. 2. Identification of two AUR complexes (1 and 2) by EMSA.

The three differents $\left[{ }^{32} \mathrm{P}\right] 3^{\prime}$ TNF RNA probes (see Fig. 1) were incubated in absence or in presence of $20 \mu \mathrm{g}$ of $\mathrm{S} 100$ cytoplasmic extracts derived from unstimulated (-) or LPS-stimulated (+) RAW264.7 macrophages.

icantly increased when cells were treated with LPS. Complex 2 was not detected when the $3^{\prime}$ TNF $\mathrm{AU}^{-}$probe was used, indicating that its formation requires the presence of AUR sequences. It should be noted that the 72 nucleotides $\mathrm{AU}^{+}$probe does not form complex 2, suggesting that LPS-inducible complex 2 involves both the AUR motif and flanking sequences.

The specificity of complexes 1 and 2 formation was further assessed by competition experiments. S100 extracts from LPS-stimulated RAW cells were incubated with equal amount of radiolabeled $3^{\prime} \mathrm{TNF} \mathrm{AU}^{+}$probe in the presence of increasing quantities of three unlabeled RNAs. Figure 3 shows that the addition of increasing amounts of unlabeled $3^{\prime}$ TNF $\mathrm{AU}^{+}$and $\mathrm{AU}^{+}$RNA efficiently compete for the formation of both complexes 1 and 2 in the EMSA. In contrast, addition of unlabeled 3' TNF $\mathrm{AU}^{-}$RNA had no effect, even at the highest concentration used in this experiment (Fig. 3). Furthermore, the formation of complexes 1 and 2 clearly resulted from the binding of proteins to the probe since pretreatment of the extracts with proteinase $\mathrm{K}$ abolished the shift of the $3^{\prime} \mathrm{TNF} \mathrm{AU}^{+}$probe without affecting its integrity (data not shown).

\section{Characterization of the Proteins Involved in Complexes 1 and 2 by UV Cross-Linking}

In order to determine the molecular weight of the proteins present in complexes 1 and 2, UV 


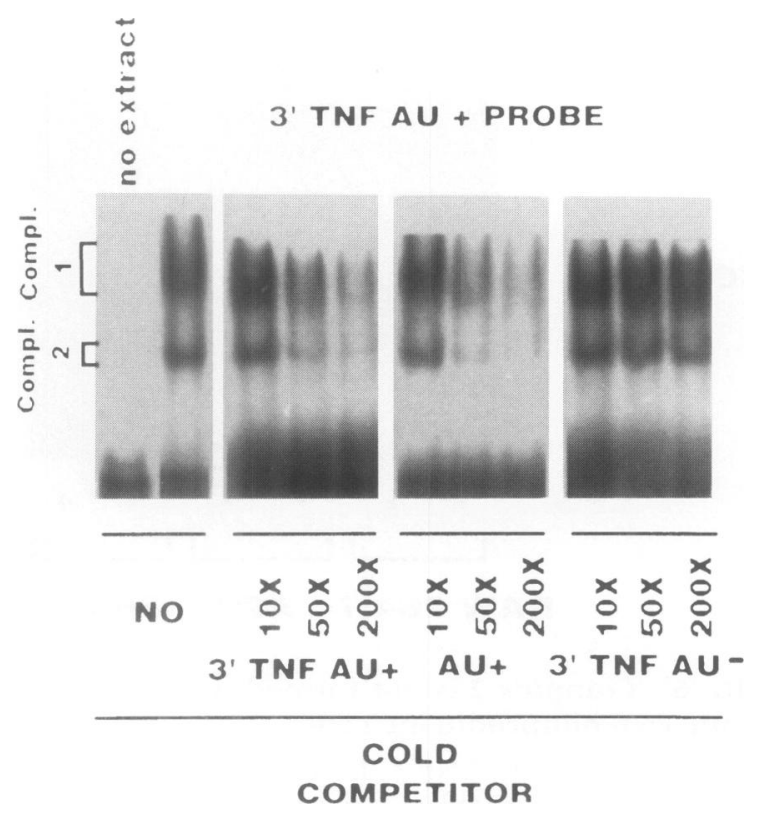

FIG. 3. Specificity of complexes 1 and 2 formation

EMSA in which S100 cytoplasmic extracts from LPSstimulated RAW cells were incubated with the $3^{\prime}$ TNF $\mathrm{AU}^{+}$probe in the absence or in the presence of $10 \times, 50 \times$, or $200 \times$ molar excess of unlabeled $3^{\prime}$ TNF $\mathrm{AU}^{+}, \mathrm{AU}^{+}$, or $3^{\prime} \mathrm{TNF} \mathrm{AU}^{-} \mathrm{RNA}$.

cross-linking and label transfer experiments were performed. As shown in Fig. 4, two proteins of apparent molecular weights of 80 and $50 \mathrm{kD}$ were detected with the $3^{\prime} \mathrm{TNF} \mathrm{AU}^{+}$probe in $\mathrm{S} 100$ extracts from both unstimulated and LPS-stimulated macrophages. The amount of $80-\mathrm{kD}$ protein bound to the probe was significantly greater in extracts obtained from unstimulated macrophages. In contrast, the amount of $50-\mathrm{kD}$ protein bound to the probe strongly increased upon LPS stimulation of the cells. No proteins binding to the $3^{\prime}$ TNF $\mathrm{AU}^{-}$probe were detected (data not shown).

\section{Infection of RAW Cells with the Sendaii Virus Induces Complex 2 Formation}

If the formation of complex 2 is related to the onset of TNF mRNA translation, other inducers of TNF mRNA translation should also trigger the formation of this complex. Viral infection is known to stimulate TNF production in macrophages (28) and, recently, Willeaume et al. (22) demonstrated that Sendaï virus triggers the translational activation of TNF mRNA in RAW cells. We therefore tested the ability of Sendaï

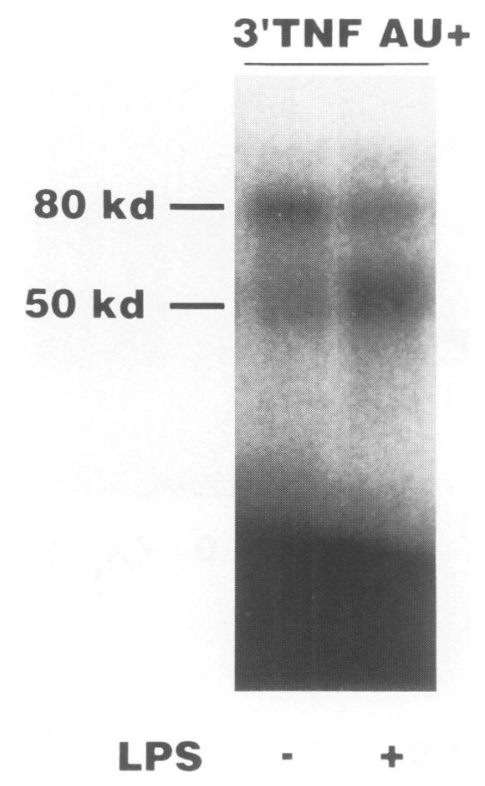

FIG. 4. Characterization of the proteins binding 3' TNF probes by UV cross-linking

Labeled $3^{\prime} \mathrm{TNF} \mathrm{AU}^{+}$probe was incubated with cytoplasmic extracts from RAW264.7 cells untreated (-) or treated (+) for $2 \mathrm{hr}$ with LPS $(10 \mathrm{ng} / \mathrm{ml})$ according to the same protocol used for EMSA. The binding reaction was subsequently UV-irradiated and treated with RNAse A. The binding proteins were resolved by SDS-PAGE (see Materials and Methods).

virus to induce complex 2 formation. RAW cells were either treated with LPS $10 \mathrm{ng} / \mathrm{ml}$ for $2 \mathrm{hr}$ or infected with Sendaï virus $(4 \% \mathrm{v} / \mathrm{v})$ for $12 \mathrm{hr}$. In both cases, high amounts of TNF were secreted by cells (Fig. 5, lower panel). The EMSA performed with $\mathrm{S} 100$ extracts from cells exposed to Sendaï virus shows that viral infection led to complex 2 formation with the same efficiency as LPS (Fig. 5, upper panel).

\section{Complex 2 Does Not Form with $\mathbf{S 1 0 0}$ Extract from Cells That Do Not Produce TNF in Response to LPS}

In order to evaluate the relationship between TNF production and complex 2 formation, we performed EMSAs with cytoplasmic extracts from unstimulated and LPS-stimulated A20 B lymphocyte cells and 3B4.15 T lymphocyte cells. Neither cell types produce TNF in response to LPS (data not shown). Unlike complex 1, complex 2 was not detected with extracts from LPSstimulated A20 or 3B4.15 cells (Fig. 6). 

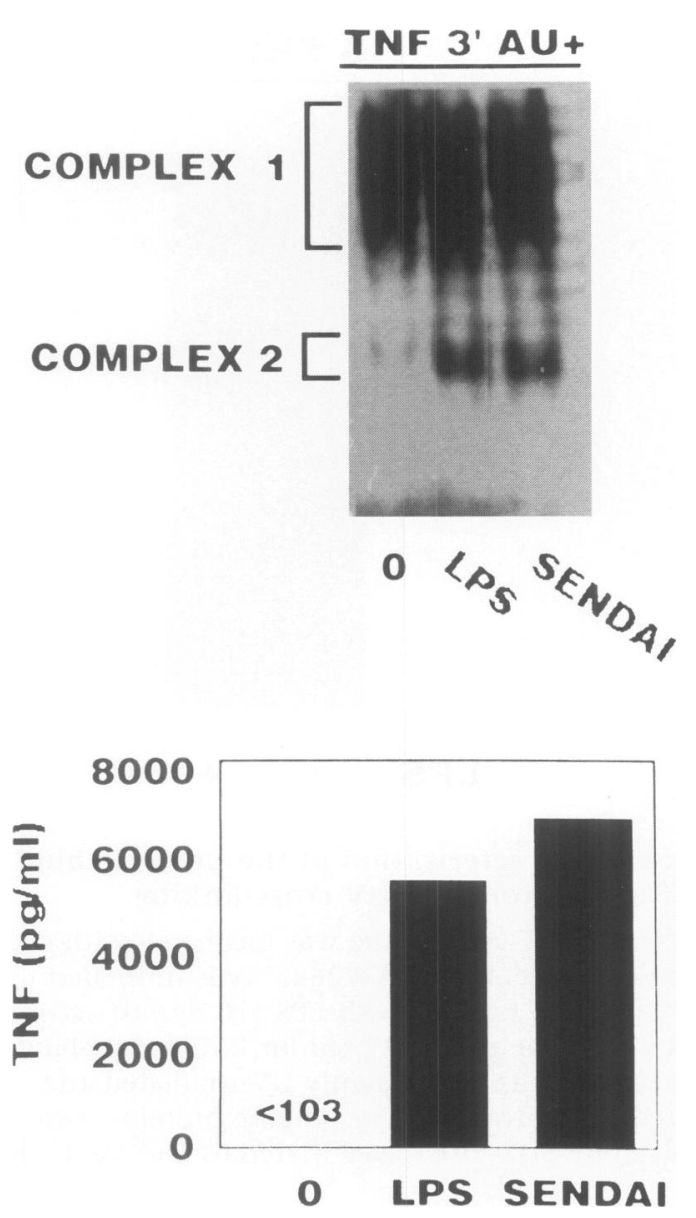

FIG. 5. Induction of complex 2 formation by Sendaï virus in RAW 264.7 cells

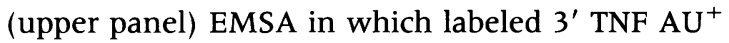
probe was incubated with cytoplasmic extracts of RAW264.7 cells unstimulated (0), stimulated by LPS (LPS) or infected with the Sendaï virus (SENDAI). (lower panel) Measurement of TNF produced by the RAW264.7 cell cultures used for cytoplasmic extract preparation.

\section{Tyrosine Kinase Inhibitor Herbimycin A Inhibits LPS-Induced Complex 2 Formation}

Protein-tyrosine phosphorylation is an early signaling event in macrophages following LPS exposure $(29,30)$ and inhibition of tyrosine phosphorylation abolishes TNF production. In addition, Willeaume et al. have recently shown that the tyrosine kinase inhibitor herbimycin A can block the translational derepression of TNF mRNA that occurs upon LPS stimulation of RAW macrophages (22). We investigated, therefore, the effect of herbimycin A on LPS-induced complex 2 formation. RAW 264.7 macrophages were
TNF 3' AU+

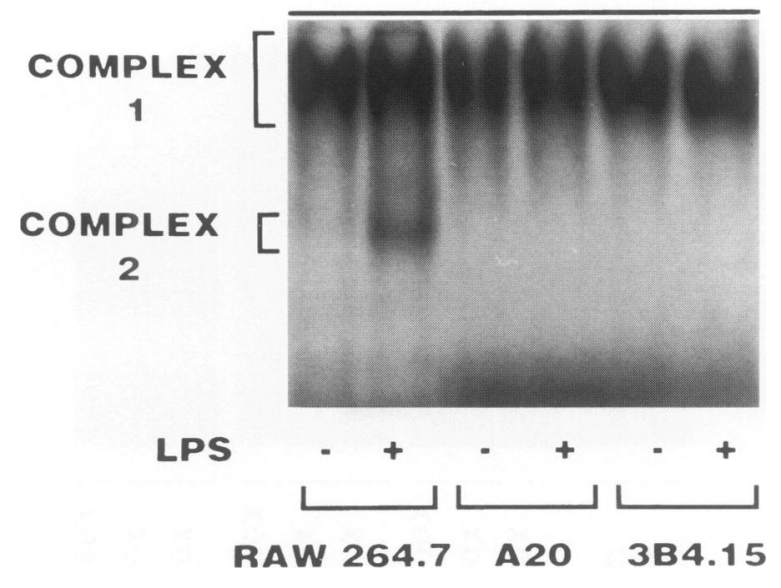

FIG. 6. Complex 2 is not formed with extracts from TNF nonproducing cells

EMSA in which the TNF 3' UTR probe was incubated with $\mathrm{S} 100$ cytoplasmic extracts prepared from RAW macrophages, 3B4.15 T cells, and A20 B cells stimulated $(+)$ or not $(-)$ by LPS $(10 \mathrm{ng} / \mathrm{ml})$ for 2 hr.

either pretreated for $2 \mathrm{hr}$ with $5 \mu \mathrm{g} / \mathrm{ml}$ of herbimycin A before LPS stimulation or left untreated. Two hours after LPS addition, the culture media were harvested to measure TNF production, and S100 extracts were prepared for EMSA analysis. Figure 7 shows that herbimycin A strongly suppressed LPS-induced complex 2 formation and TNF synthesis.

\section{Kinetics and LPS Dose-Dependence of Complex 2 Formation}

In order to assess further the biological significance of complex 2 formation in relationship with TNF production, we performed kinetic and LPS dose-response experiments. RAW264.7 cells were exposed to $10 \mathrm{ng} / \mathrm{ml}$ of LPS for increasing time periods before $S 100$ extract preparation. As shown in Fig. 8A, complex 2 formation parallels TNF production and is clearly detectable as early as $0.5 \mathrm{hr}$ after LPS addition to the cell culture.

Complex 2 formation and TNF production were analyzed after stimulation of RAW 264.7 macrophages with increasing concentrations of LPS for $2 \mathrm{hr}$. LPS concentrations as low as $10 \mathrm{pg} / \mathrm{ml}$ were sufficient to induce both complex 2 formation and TNF production. Treatment of the cells with increasing doses of LPS led to increases in both complex 2 intensity and TNF production (Fig. 8B). 

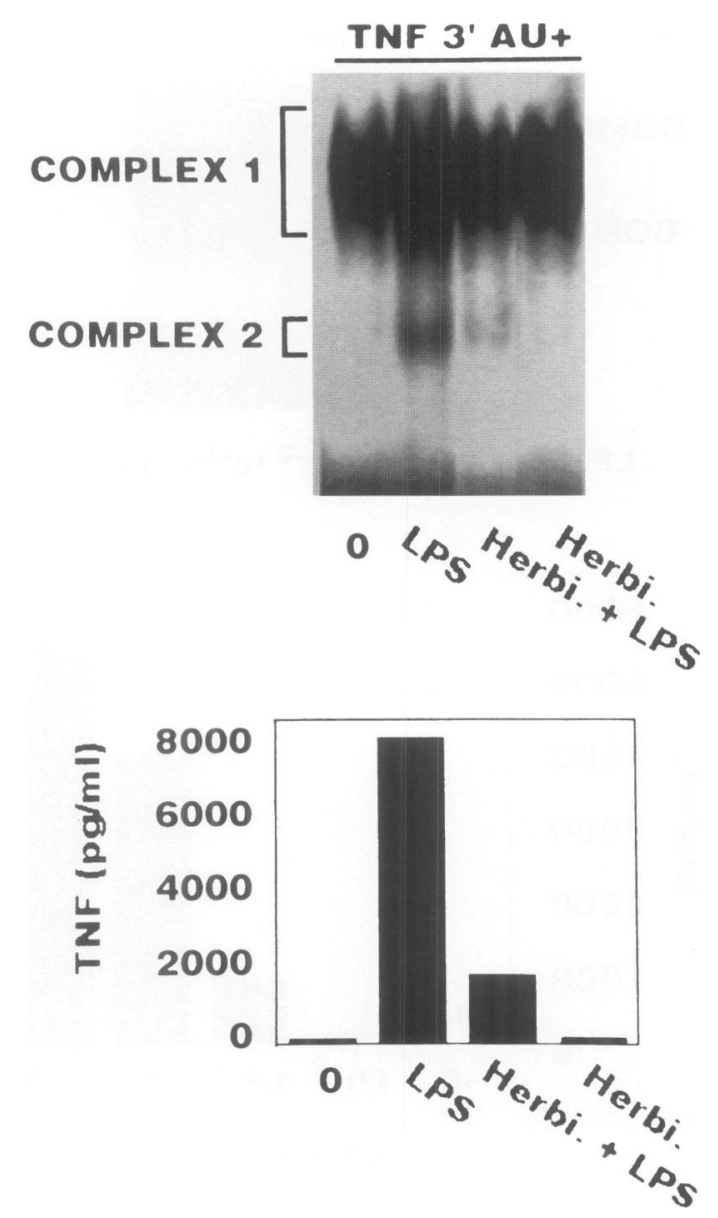

FIG. 7. Inhibition of complex 2 formation by herbymicin A

(upper panel) EMSA in which labeled $3^{\prime} \mathrm{TNF} \mathrm{AU}^{+}$ probe was incubated with cytoplasmic extracts from RAW264.7 cells treated or not with LPS $(10 \mathrm{ng} / \mathrm{ml})$ for $2 \mathrm{hr}$. When treated with herbimycin A, the cells were incubated in the presence of this agent $(5 \mu \mathrm{g} /$ $\mathrm{ml})$ for $2 \mathrm{hr}$ before LPS addition to the cultures. The treatment applied to each cell culture is specified below each lane. (lower panel) Measurement of TNF produced by RAW264.7 cell cultures used for cytoplasmic extract preparation.

\section{DISCUSSION}

We report the identification of two protein complexes ( 1 and 2 ) that specifically involve the AUR sequence of TNF $\alpha$ mRNA. Remarkably, formation of complex 2 is dependent on the activation state of the cells. While it is hardly detectable in EMSA performed with cytoplasmic extracts from unstimulated RAW cells, complex 2 is readily observed with cytoplasmic extracts obtained from LPS-stimulated RAW cells.

Both complexes 1 and 2 specifically involve the TNF mRNA AUR sequence since removal of this sequence abolishes the formation of both complexes. Complex 2 is detected only when the 513 nucleotides probe containing the AUR together with its flanking sequences $\left(3^{\prime} \mathrm{TNF} \mathrm{AU}^{+}\right.$) is used, and not with the shorter $72 \mathrm{nt} \mathrm{AU}^{+}$ probe. Competition experiments, however, show that this shorter $\mathrm{AU}^{+}$RNA effectively impairs the formation of complex 2 by the $3^{\prime} \mathrm{TNF} \mathrm{AU}^{+}$RNA. These observations suggest that the AUR element is recognized by factor(s) necessary for complex 2 formation, but that the stabilization of this complex requires either additional flanking sequences or additional proteins that interact with these sequences. In this regard, it has been shown that the AUR sequence is necessary but not sufficient to confer LPS inducibility to a CAT reporter gene and that the presence of additional flanking sequences from TNF mRNA 3' UTR are also required $(19,20)$.

UV cross-linking and label transfer experiments demonstrate that S100 extracts of RAW macrophages contain two proteins of 50 and 80 $\mathrm{kD}$ which bind TNF mRNA AUR sequence. While the amount of $80-\mathrm{kD}$ binding protein decreases upon stimulation of the cells with LPS, the amount of $50-\mathrm{kD}$ binding protein increases. Although the association of the $50-$ and $80-\mathrm{kD}$ proteins to one or the other complexes remains speculative, these data suggest that the $50-\mathrm{kD}$ protein might be the component of complex 2 involved in the recognition of the RNA target sequence.

The biological significance of complex 2 formation with respect to TNF mRNA translational activation is supported by the following findings: (i) two unrelated inducers of TNF mRNA translation (LPS and Sendai virus) can promote complex 2 formation; (ii) complex 2 is not observed upon LPS stimulation of A20 B cells or 3B4.15 T cells which do not produce TNF in response to LPS; (iii) preincubation of cells with the tyrosine phosphorylation inhibitor herbimycin A, which is known to abrogate LPS-induced TNF mRNA translational activation (22), abolishes complex 2 formation induced by LPS; (iv) the kinetics of complex 2 formation closely parallels the induction of TNF upon LPS stimulation; and $(v)$ very low doses of LPS, sufficient to trigger TNF production in RAW cells, also promote complex 2 formation.

A recent report shows that in unstimulated macrophages TNF mRNA remains unbound to the translational machinery or is sequestered in a 43S preinitiation complex. Upon stimulation with LPS, TNF mRNA shifts into the polyribo- 
A

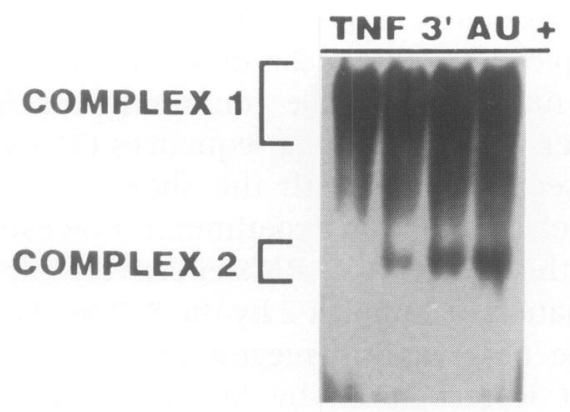

TIME (hours) $0 \begin{array}{llll}0 & 0.5 & 1 & 2\end{array}$

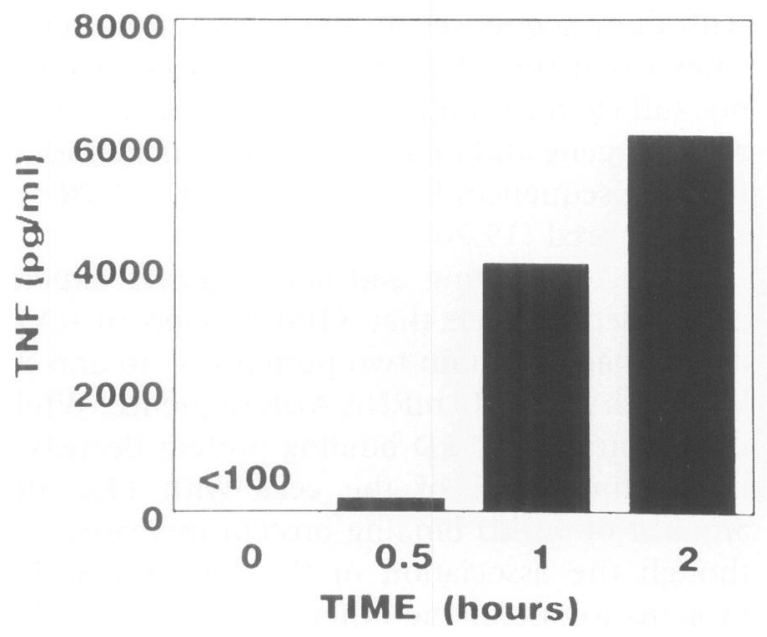

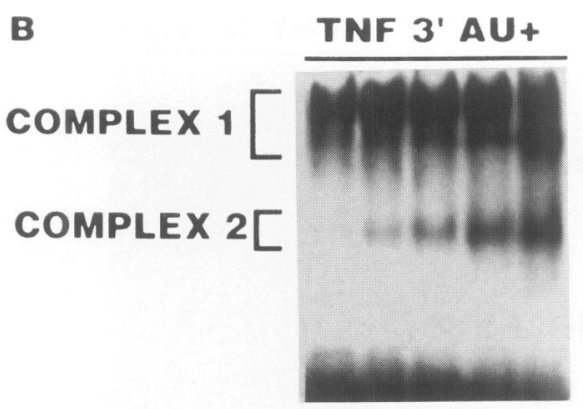

LPS (ng/ml) $010^{-2} 10^{-1} 110$

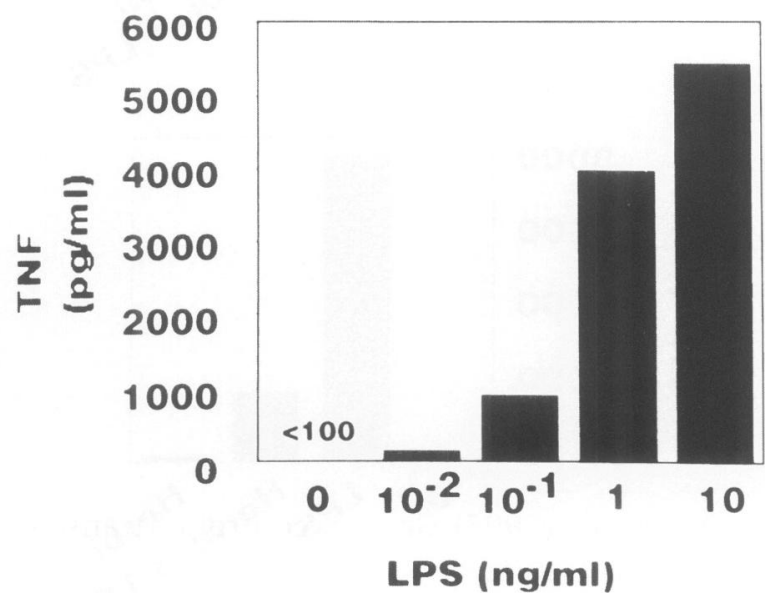

FIG. 8. Kinetics (A) and LPS dose dependence (B) of complex 2 formation

(A) Upper panel: S100 cytoplasmic extracts were prepared from RAW cells stimulated by LPS (10 ng/ml) for 0 , $0.5,1$ or $2 \mathrm{hr}$ and analysed by EMSA using the $3^{\prime} \mathrm{TNF} \mathrm{AU}^{+}$probe. Lower panel: measurement of TNF secreted by the cell cultures used for cytoplasmic extract preparation. (B) Upper panel: EMSA in which S100 cytoplasmic extracts from RAW264.7 macrophages treated for $2 \mathrm{hr}$ with increasing doses of LPS were incubated with labeled 3' TNF $\mathrm{AU}^{+}$probe. LPS doses are indicated at the bottom of the figure. Lower panel: measurement of TNF produced by RAW264.7 macrophage cultures used for extract preparation.

somes (31). These data suggest that TNF mRNA translation is controlled at an early step of mobilization or initiation. Based on these observations, we speculate that complex 2 formation is a prerequisite step for the targeting of TNF mRNA to the translation machinery since the complex 2 is observed with cytosolic extract and not with a salt wash of the ribosomal pellet (data not shown). This event is dependent on tyrosine phosphorylation since complex 2 formation is inhibited by the protein-tyrosine kinase inhibitor herbimycin A.

Several cytoplasmic proteins binding to AUR sequences have been identified so far $(11,12,14,32)$. These proteins were, however, only found in cells where the destabilizing effect of the AUR sequences has been observed. While some of these factors bind constitutively to the sequence, others are induced by certain stimuli. Indeed, Bohjanen et al. identified two other proteins of 30 and $43 \mathrm{kD}$ which bind to the AUR sequence upon activation of $\mathrm{T}$ lymphocytes with anti-CD3 antibodies $(14,33)$. Based on apparent molecular weight and subcellular localisation, the 80 - and $50-\mathrm{kD}$ proteins identified in this study seem not to be related to any of these previously identified proteins.

The precise characterization of the proteins involved in the LPS-inducible complex and the cloning of the corresponding genes will provide more insight into the understanding of TNF mRNA translational regulation. 


\section{ACKNOWLEDGMENTS}

We thank Oberdan Leo, Patrice Dubois, and Serge Barcy for helpful discussion; Zoulikka Amraoui for help with the TNF ELISA; Véronique Willeaume for providing us the AU+ DNA construct; and Fabienne Andris for the 3B4.15 cell line. This work was supported by the "Fonds pour la Recherche Scientifique Médicale" (Belgium, Grant 3.4586.93), the "Fonds de la Recherche Fondamentale Collective" (Grant 2.4572.93), the "Fonds Dehousse," the Belgian sport association against cancer and by a grant from "Actions de Recherches Concertées" (Contract 94/99-181). C. Gueydan and L. Houzet are supported by the "Fonds des bourses de l'U.L.B."

\section{REFERENCES}

1. Jackson RJ. (1993) Cytoplasmic regulation of mRNA function: The importance of the 3' untranslated region. Cell 74: 9-14.

2. Atwater JA, Wisdom R, Verma IM. (1990) Regulated mRNA stability. Annu. Rev. Genet. 24: 519-541.

3. Morris D. (1995) Growth control of translation in mammalian cells. Prog. Nucleic. Acid. Res. Mol. Biol. 51: 339-362.

4. Beelman CA, Parker R. (1995) Degradation of mRNA in eukaryotes. Cell 81: 179-183.

5. Caput D, Beutler B, Hartog K, Thayer R, Brown Shimer S, Cerami A. (1986) Identification of a common nucleotide sequence in the 3'-untranslated region of mRNA molecules specifying inflammatory mediators. Proc. Natl. Acad. Sci. U.S.A. 83: 1670-1674.

6. Shaw G, Kamen R. (1986) A conserved AU sequence from the $3^{\prime}$ untranslated region of GM-CSF mRNA mediates selective mRNA degradation. Cell 46: 659-667.

7. Wilson T, Treisman R. (1988) Removal of poly(A) and consequent degradation of c-fos mRNA facilitated by $3^{\prime}$ AU-rich sequences. Nature 336: 396-399.

8. Kruys V, Huez G. (1994) Translational control of cytokine expression by $3^{\prime}$ UA-rich sequences. Biochimie 76: 862-866.

9. Lagnado CA, Brown CY, Goodall GJ. (1994) AUUUA is not sufficient to promote poly(A) shortening and degradation of an mRNA: The functional sequence within AU-rich elements may be UUAUUUA(U/A)(U/A). Mol. Cell. Biol. 14: 7984-7995.

10. Zubiaga AM, Belasco JG, Greenberg ME.
(1995) The nonamer UUAUUUAUU is the key AU-rich sequence motif that mediates mRNA degradation. Mol. Cell. Biol. 15: 22192230.

11. Malter JS. (1989) Identification of an AUUUA-specific messenger RNA binding protein. Science 246: 664-666.

12. Vakalopoulou E, Schaack J, Shenk T. (1991) A 32-kilodalton protein binds to AU-rich domains in the 3' untranslated regions of rapidly degraded mRNAs. Mol. Cell. Biol. 11: 3355-3364.

13. Brewer G. (1991) An A + U-rich element RNA-binding factor regulates c-myc mRNA stability in vitro. Mol. Cell. Biol. 11: 24602466.

14. Bohjanen $\mathrm{PR}$, Petryniak $\mathrm{B}$, June $\mathrm{CH}$, Thompson CB, Lindsten T. (1991) An inducible cytoplasmic factor (AU-B) binds selectively to AUUUA multimers in the $3^{\prime}$ untranslated region of lymphokine mRNA. Mol. Cell. Biol. 11: 3288-3295.

15. Kruys V, Wathelet $M$, Poupart $P$, et al. (1987) The 3' untranslated region of the human interferon-beta mRNA has an inhibitory effect on translation. Proc. Natl. Acad. Sci. U.S.A. 84: 6030-6034.

16. Kruys VI, Wathelet MG, Huez GA. (1988) Identification of a translation inhibitory element (TIE) in the $3^{\prime}$ untranslated region of the human interferon-beta mRNA. Gene 72: 191-200.

17. Kruys V, Marinx O, Shaw G, Deschamps J, Huez G. (1989) Translational blockade imposed by cytokine-derived UA-rich sequences. Science 245: 852-855.

18. Kruys V, Kemmer K, Shakhov A, Jongeneel V, Beutler B. (1992) Constitutive activity of the tumor necrosis factor promoter is canceled by the $3^{\prime}$ untranslated region in nonmacrophage cell lines; A trans-dominant factor overcomes this suppressive effect. Proc. Natl. Acad. Sci. U.S.A. 89: 673-677.

19. Han J, Brown T, Beutler B. (1990) Endotoxin-responsive sequences control cachectin/ tumor necrosis factor biosynthesis at the translational level [published erratum appears in $J$ Exp Med 1990 Mar 1;171: 971972]. J. Exp. Med. 171: 465-475.

20. Han J, Beutler B. (1990) The essential role of the UA-rich sequence in endotoxin-induced cachectin/TNF synthesis. Eur. Cytokine Netw. 1: $71-75$.

21. Han JH, Beutler B, Huez G. (1991) Complex regulation of tumor necrosis factor mRNA 
turnover in lipopolysaccharide-activated macrophages. Biochim. Biophys. Acta 1090: 22-28.

22. Willeaume V, Kruys V, Mijatovic T, Huez G. (in press) TNF- $\alpha$ production induced by viruses and by LPS in macrophages: Similarities and differences. J. Inflamm.

23. Beutler B, Brown T. (1991) A CAT reporter construct allows ultrasensitive estimation of TNF synthesis, and suggests that the TNF gene has been silenced in non-macrophage cell lines. J. Clin. Invest. 87: 1336-1344.

24. Andris F, Leo O, Van Mechelen M, Urbain J, Slaoui M. (1989) CD4-Ia interactions can occur in the absence of T-cell receptor/antigen-Ia recognition. Immunology 68: 1-6.

25. Dignam JD, Lebovitz RM, Roeder RG. (1983) Accurate transcription initiation by RNA polymerase II in a soluble extract from isolated mammalian nuclei. Nucleic Acids Res. 11: 1475-1489.

26. Konarska MM, Sharp PA. (1986) Electrophoretic separation of complexes involved in the splicing of precursors to mRNAs. Cell 46: 845-855.

27. Leibold EA, Munro HN. (1988) Cytoplasmic protein binds in vitro to a highly conserved sequence in the $5^{\prime}$ untranslated region of ferritin heavy- and light-subunit mRNAs. Proc. Natl. Acad. Sci. U.S.A. 85: 2171-2175.

Contributed by A. Cerami on April 17, 1996.
28. Aderka D, Holtmann H, Toker L, Hahn T, Wallach D. (1986) Tumor necrosis factor induction by Sendai virus. J. Immunol. 136: 2938-2942.

29. Weinstein SL, June $\mathrm{CH}$, DeFranco AL. (1993) Lipopolysaccharide-induced protein tyrosine phosphorylation in human macrophages is mediated by CD14. J. Immunol. 151: 3829-3838.

30. Weinstein SL, Gold MR, DeFranco AL. (1991) Bacterial lipopolysaccharide stimulates protein tyrosine phosphorylation in macrophages. Proc. Natl. Acad. Sci. U.S.A. 88: 4148-4152.

31. Prichett W, Hand A, Shields J, Dunnington D. (1995) Mechanism of action of bicyclic imidazoles defines a translational regulatory pathway for tumor necrosis factor alpha. J. Inflamm. 45: 97-105.

32. Zhang W, Wagner BJ, Ehrenman $\mathrm{K}$, et al. (1993) Purification, characterization, and cDNA cloning of an AU-rich element RNAbinding protein, AUF1. Mol. Cell. Biol. 13: 7652-7665.

33. Bohjanen $P R$, Petryniak $B$, June $\mathrm{CH}$, Thompson CB, Lindsten T. (1992) AU RNAbinding factors differ in their binding specificities and affinities. J. Biol. Chem. 267: 6302-6309. 